\title{
Docência na educação profissional: um olhar sobre o reconhecimento e validação dos saberes experienciais
}

Rodrigo Ademar Bender ${ }^{1}$

Sita Mara Lopes Sant'Anna ${ }^{2}$

\section{Resumo}

Neste artigo, problematizam-se questões ligadas à docência na Educação Profissional, conjugadas ao reconhecimento dos saberes experienciais que os sujeitos jovens, adultos e idosos trazem consigo. Efetiva-se pesquisa qualitativa, exploratória e descritiva. Apresenta-se um apanhado bibliográfico dos conceitos de base, e debatem-se perspectivas possíveis do arcabouço teórico-metodológico da Análise de Discurso de Linha Francesa de Michel Pêcheux (1993) para o corpus analítico. Como resultados se destaca que a tensão do reconhecimento e validação dos saberes experienciais apontados nos discursos remonta a memórias impregnadas de historicidade e trabalha a ideologia como materialmente relacionada às práticas docentes, orientando reflexões finais sobre o papel docente.

Palavras-chave: Educação Profissional; Validação de Saberes; Docência; Análise de Discurso.

La enseñanza en la educación profesional: una mirada al reconocimiento / validación del conocimiento experiencial

\section{Resumen}

Este artículo aborda temas relacionados con la enseñanza en la educación profesional, combinada con el reconocimiento del conocimiento experimental que los sujetos jóvenes, adultos y ancianos traen consigo. Se realiza investigación cualitativa, exploratoria y descriptiva. Se presenta una descripción bibliográfica de los conceptos básicos y se discuten las posibles perspectivas del marco teórico-metodológico del Análisis del discurso de la línea francesa de Michel Pêcheux (1993) para el corpus analítico. Como resultado, se destaca que la tensión de reconocimiento / validación del conocimiento experiencial señalado en los discursos, se remonta a recuerdos impregnados de historicidad e ideología del trabajo como materialmente relacionado con las prácticas de enseñanza, guiando las reflexiones finales sobre el papel de la enseñanza.

Palabras clave: Educación Profesional; Validación de Conocimiento; Enseñanza; Análisis del Discurso.

\section{Introdução}

A Educação Profissional (EP), como modalidade da Educação Básica, sofre influências da tendência adotada no Brasil, desde os anos 1990, que tem nos processos de reestruturação do Estado e da economia, o viés liberalizante e que procurara colocar em prática uma agenda de desenvolvimento, sob inspiração de agências e organismos internacionais, como o Fundo

\footnotetext{
${ }^{1}$ Universidade Estadual do Rio Grande do Sul (UERGS/PPGED-MP), Osório/RS, rodrigo-bender@uergs.edu.br

2 Universidade Estadual do Rio Grande do Sul, (UERGS/PPGED-MP), Osório/RS, sita-santanna@uergs.edu.br
} 
Monetário Internacional e o Banco Mundial, especialmente (JÚNIOR; MAUÉS, 2014). Assim, a formulação das políticas educacionais parte da ideia de que a flexibilização do mercado de trabalho exige a incorporação de habilidades e competências para além da formação, adequadas desde o modelo taylorista e/ou fordista ${ }^{3}$ (RIBEIRO, 2015). Nesta perspectiva, as demandas de qualificação referem-se à emergência de um trabalhador com maior responsabilidade, autonomia, flexibilidade, portador de capacidade de adequação de produção e consumo flexíveis, em um contexto produtivo que reunifica saber e fazer, além de valorizar sua condição subjetiva, singularizada, múltipla, mas sob a égide do processo de acumulação e/ou mercantilização.

Como efeito, a atual política pública educacional e, em sequência, a legislação da educação brasileira, particularmente através da Lei de Diretrizes e Bases da Educação Nacional LDBEN (BRASIL, 1996), reproduzem esses preceitos e valores, que conforme Rosa, Sant'Anna e Stramare (2019), reproduzem padrões de qualidade e práticas que influenciam a docência no âmbito da educação das pessoas jovens e adultas, embora a educação voltada a esse público tenha por princípio o processo de escuta da realidade na modalidade Educação de Jovens e Adultos - EJA (FREIRE, 1997).

Diante deste contexto, torna-se relevante que esse artigo se proponha a debater questões ligadas à pesquisa sobre docência, conjugada, especificamente, sobre o desafio do reconhecimento dos saberes experienciais que os sujeitos jovens, adultos e idosos trazem consigo e da percepção de como estes são percebidos/abrangidos na Educação Profissional. Em especial, busca-se refletir a interface existente entre os saberes experienciais e epistêmicos presentes nesta modalidade de educação, valorizando as aprendizagens não-formais e informais que os sujeitos adultos realizam ao longo de suas trajetórias pessoais, sociais e profissionais.

Nesta perspectiva, esse artigo apresenta referencial bibliográfico e conceitual ligados à Educação Profissional, à docência e à teoria e prática educativa considerando o reconhecimento dos saberes experienciais. Posteriormente, apresenta descrição dos sujeitos envolvidos e seu contexto atual de atuação profissional, o contorno do caminho metodológico e em seguida, enfatiza

\footnotetext{
3 Taylorismo: sistema de organização do trabalho concebido pelo engenheiro norte-americano Fredeick Winslow Taylor (1856 - 1915), com o qual se pretende alcançar o máximo de produção e rendimento com o mínimo de tempo e esforço. Fordismo: termo criado pelo empresário estadunidense Henry Ford, em 1914, referindo-se aos sistemas de produção e gestão, baseados em "linha de produção", ou seja, em massa, idealizados pelo mesmo em 1913 (RIBEIRO, 2015).
} 
a explicitação teórico-metodológica da Análise de Discurso $(A D)$ da linha francesa de Michel Pêcheux (1993), a qual fundamenta a análise do material linguístico coletado e nos auxilia a perceber alguns implícitos, presentes nos discursos dos sujeitos participantes da pesquisa. Por fim, reflete-se sobre o reconhecimento e validação dos saberes experienciais e os achados analíticos, tendo por base as lógicas que se encontram em presença e no domínio da docência. Desta forma, espera-se contribuir com estudos e reflexões sobre a docência na Educação Profissional.

\section{Educação profissional, docência e discurso pedagógico}

Entende-se por Educação Profissional (EP), nesse estudo, o que propõe a atual LDBEN (BRASIL, 1996) que a considera como apresentado na Seção IV, Artigo 36 - Parágrafo único, na perspectiva de que "a preparação geral para o trabalho e, facultativamente a habilitação profissional poderão ser desenvolvidas nos próprios estabelecimentos de ensino médio ou em cooperação com instituições especializadas em Educação Profissional”.

Conforme Oliveira (2016) aponta, necessita-se observar o pressuposto histórico da EP, detendo atenção ao Decreto no 7.566, que a estabeleceu, em diferentes estados do país, em 1909; as Escolas de Aprendizes Artífices ${ }^{4}$, destinadas ao ensino profissional, primário e gratuito. Porém, não se pode deixar de lembrar do seu viés instrumental, voltado à preparação para o trabalho manual, em oposição à formação acadêmica, esta, destinada às elites, como apresenta Ferretti (2010).

Com isso, num salto histórico, o olhar é lançado para os anos de 2008 e 2017, chamando a atenção sobre as Leis: Lei 11.741 (BRASIL, 2008) que estabelece as diretrizes e bases da educação nacional, para redimensionar, institucionalizar e integrar as ações da Educação Profissional técnica de nível médio, da Educação de Jovens e Adultos e da Educação Profissional e tecnológica e a Lei no 13.415 (BRASIL, 2017), que também introduziu alterações na LDBEN 9394 (BRASIL, 1996) incluindo o itinerário formativo ${ }^{5}$ da "Formação Técnica e Profissional" no ensino médio.

\footnotetext{
${ }^{4}$ Consistiam numa formação profissional de base prática, voltada para as classes populares, para os desfavorecidos da fortuna, evitando-se com isso, que em sua ociosidade, se tornassem criminosos.

${ }^{5}$ Tem-se que o currículo do ensino médio será composto pela Base Nacional Comum Curricular e por itinerários formativos, que deverão ser organizados por meio da oferta de diferentes arranjos curriculares, conforme a relevância para o contexto local e a possibilidade dos sistemas de ensino.
} 
Diante desse contexto, a Educação Profissional será entendida por sua ocorrência na Educação Básica, e como tal, conforme a LDBEN 9394 (BRASIL, 1996), de acordo com o Artigo 36C, poderá ocorrer de forma integrada, concomitante e/ou subsequente ${ }^{6}$.

Por docência entende-se, a partir das reflexões de Laffin $(2013$, p.81), que a mesma compreende as "múltiplas dimensões e concepções presentes no fazer docente". Essa multidimensionalidade que envolve concepções, processos e práticas, dentre elas, a de ensino na sala de aula, produz processos identitários profissionais como sempre em construção, de modo inacabado, provisório (relacionado a uma lógica de incompletude) e em permanente movimento de constituição.

De acordo com Freire (1997), mesmo diante do inacabamento e das instabilidades presentes nas relações cotidianas, à docência está implicada no rigor ético dos processos reflexivos. Nessa perspectiva, Freire $(1997$, p.18) afirma:

A ética que falo é a que se sabe afrontada na manifestação discriminatória de raça, de gênero, de classe. É por essa ética inseparável da prática educativa, não importa se trabalhamos com crianças, jovens ou com adultos, que devemos lutar. E a melhor maneira de por ela lutar, é vivê-la em nossa prática, é testemunhá-la vivaz, aos educandos em nossa relação com eles.

É importante destacar, também, que para Freire (1997) à docência compreende a "dodiscência"7, em que o ensinar e o aprender dialogam como postura epistemológica que precisa ser assumida pelo professor/professora. Como é possível observar, o estudo sobre a docência envolve uma complexidade abrangente, então, neste artigo articular-se-á docência, à postura epistemológica assumida e não negada, expressa no Discurso Pedagógico (DP), percebido pelos participantes da pesquisa.

Por Discurso Pedagógico se entende o que propõe Orlandi (1983) que o estudou e o definiu como ligado ao ato de ensinar. Em seu estudo, a autora definiu o DP como autoritário,

\footnotetext{
${ }^{6}$ Forma integrada: oferecida somente a quem já tenha concluído o ensino fundamental, sendo o curso planejado de modo a conduzir o aluno à habilitação profissional técnica de nível médio; Forma concomitante: oferecida a quem ingresse no ensino médio ou já o estejam cursando; Forma subsequente: oferecida a quem já tenha concluído o ensino médio.

${ }^{7}$ A esse respeito, Freire, numa dimensão docente humanizada, chama a atenção sobre a necessidade de se considerar a alteridade discente na práxis docente, a qual implica dizer que não há docência sem discência, ou simplesmente, dodiscência, já que, quem ensina aprende ao ensinar e quem aprende ensina ao aprender (FREIRE, 1997).
} 
elencando a ele caraterísticas relativas ao seu funcionamento. Como efeito de um processo histórico em nossas memórias e, de acordo com o seu referente, conforme a autora, o Discurso Pedagógico, tal como o conhecemos, historicamente, e dele nos apropriamos, influencia e pode inculcar saberes e ideologias, tendo as suas mediações preenchidas, de uma forma geral, pelas ideologias dominantes que o constituem e comportam. De acordo com o seu referente, temática, abordagem a ensinar, haveria um apagamento "natural "da origem do conhecimento, pelo professor, de boa parte do que enuncia, estabelecendo-se, no DP, uma relação autoritária histórica de quem ensina e quem aprende. Para que esse cenário se modifique, a autora propõe que o DP, tipificado por ela, se abra para a presença, em seu interior, de outros tipos de discursos, como o Lúdico e o Polêmico. Assim, uma tensão entre quem ensina e quem aprende se estabelece demarcada pela presença de outros tipos de discurso, que têm a polissemia mais presente. São esses os discursos que, segundo a autora, flexibilizariam, tornariam o DP menos autoritário.

De um modo geral sobre a sua tipificação, ao pensarmos ao nível da metalinguagem, considerando a palavra para explicar a palavra, explicita que o DP possui definições rígidas (do tipo "é porque é"), cortes polissêmicos (polissemia contida), direcionamentos organizados que conduzem a conclusões unívocas (ORLANDI, 2008). Já em níveis de cientificidade, ou seja, da natureza da informação, o seu conteúdo se apresenta como um saber institucionalizado, como é, sem demandar o questionamento legítimo estando quase sempre condicionado "ao que deve ser", a informação, quase sempre sem a autoria originária, que é frequente no DP.

Nesta perspectiva, enquanto instituição que historicamente legitima o DP, a escola é vista como a sede desse discurso, convertendo o mesmo em hierarquias sociais e em hierarquias escolares, como forma de legitimação e perpetuação de uma ordem social dada, numa convenção em que a mesma atua, como um modelo instituído, obrigatório. Portanto, o DP considerado como um dizer institucionalizado "na escola", a garante, como sede socialmente reconhecida, que se origina e tende, numa forma intencional dada, a perpetuar concepções, valores etc.

Por se pensar em educar os jovens, adultos e idosos ${ }^{8}$, que são o público da Educação Profissional e, parafraseando Santos (2019), mesmo se tendo consciência de que a Educação

\footnotetext{
${ }^{8}$ Como referenciado nos estudos de Doll (2015), no artigo intitulado "Educação e Envelhecimento". Educação \& Realidade, Porto Alegre, v.40, n.1, p.9-15, jan./mar. 2015. Disponível em: http://www.ufrgs.br/edu_realidade. Acesso em: 12 ago. 2019.
}

Periódico Horizontes - USF - Itatiba, SP - Brasil - e020061 
Profissional não é a modalidade EJA, percebe-se que o público de ambas se equivalem, ou ainda, por outras questões, passa-se a utilizar a sigla EJAI (Educação de Jovens, Adultos e Idosos), em algumas situações. Da EP muitos desses jovens, adultos e idosos que frequentam a Educação Profissional se encontram em condições de não empregados, desempregados, empregados em ocupações precárias e vacilantes, e podem encontrar nos espaços e tempos da EJAI, seja em suas funções de reparação ${ }^{9}$ e de equalização, ou na função de qualificação, um lugar de melhor capacitação para o mundo do trabalho e para a atribuição de significados às aprendizagens formais e não-formais que adquiriram ao longo de suas trajetórias pessoais, sociais e profissionais.

A Constituição Federativa atual (BRASIL, 1988), em seu artigo 205, incorporou como princípio que "toda e qualquer educação visa ao pleno desenvolvimento da pessoa, seu preparo para o exercício da cidadania e sua qualificação para o trabalho". Retomado pelo art. 2ㅇ da LDBEN (BRASIL, 1996), este princípio abriga o conjunto das pessoas e dos educandos, como um universo de referências. A institucionalização do DP também precisa ser analisada sob essas relações.

\section{Um contexto de mudança: a prática educativa e o reconhecimento dos saberes experienciais}

Propõe-se, aqui, outro viés para os fenômenos educativos calcados no paradigma de aprendizagem ao longo da vida, ou seja, numa ruptura de fronteiras na delimitação dos espaçostempos formais de aprendizagem, num sentido de elaboração de formas de reconhecer e validar os saberes experienciais dos sujeitos jovens, adultos e idosos quando do momento de sua escolarização.

Inscreve-se, desta forma, em se tratando da EJAI, um cenário que valoriza os saberes das trajetórias pessoais, sociais e profissionais, ao passo que atenua a fronteira entre educação, formação e trabalho, constituindo-se, assim, como um novo paradigma aos sistemas de educação/formação na atualidade.

Apoiando-se em Nóvoa apud Pires (2007, p.7), há saberes que funcionam como modelos

\footnotetext{
${ }^{9}$ Conforme o Parecer 11 (BRASIL, 2000), a EJA, que acolhe pessoas adolescentes, jovens, adultas e idosas possui funções reparadoras, qualificadoras e equalizadoras. Essas funções emitem à EJA atribuições de atendimento à dívida social com igualdade, qualidade equidade para todos e todas.
} 
referenciados, "os quais ultrapassam as fronteiras tradicionais - construídos através de redes, articulações e filiações - e que, ao serem apropriados pelos actores, transformam as práticas locais de acção". Com isso, os saberes adquiridos, para além do sistema formal de educação, requerem um caráter de reconhecimento e validação urgente, pois, conforme enuncia Pires (2007, p.7):

[...] têm inegavelmente um valor pessoal, formativo, profissional, social e econômico. E têm vindo a ser cada vez mais valorizados, quanto mais se acentua a rapidez das mudanças sociais, científicas, tecnológicas e econômicas, que caracterizam a sociedade contemporânea, e que colocam novos e significativos desafios ao nível do conhecimento necessário - não apenas para lidar com as mudanças em curso, mas também para participar criticamente nos processos de mudança.

Verifica-se, então, uma necessária reavaliação de como os sistemas formais de educação farão o reconhecimento destes saberes experienciais, pois os mesmos desenvolveram-se ou desenvolvem-se numa multiplicidade de situações e contextos de vida. Assim, estes obedecem a uma ordem própria em sua elaboração, como também, sua difusão é distinta daquela do sistema educacional tradicional (dotado de modelos, práticas, disciplina e transmissão).

Assim, corrobora Alcoforado (2014, p.15):

O mundo do trabalho foi o primeiro a sentir-se desafiado por essa dinâmica de práticas e esses desafios de construção e validação de diferentes formas de conhecimento! Enquanto espaço de (im)previsibilidade, tensão e continuidade entre dimensões individuais e coletivas, saberes transmitidos e saberes construídos e intenção e desempenho, o trabalho sempre necessitou de encontrar formas de reconhecimento pessoal e social, prévias ou posteriores à ação profissional, capazes de estruturar uma ordem social, construída através de negociações, que se pretendem justas e equilibradas, entre os diferentes agentes. A certificação de saberes experienciais e de competências situa-se, exatamente, no centro dessa procura e de um debate que já leva alguns anos e se constitui como um dos grandes desafios para a Pedagogia, nos próximos anos.

O que se pensa aqui, por assim dizer, propõe uma cisão ao nível epistemológico, conduzindo a uma mudança no paradigma teórico, metodológico, ou seja, os saberes experienciais com um "novo estatuto" frente ao saber escolar institucionalizado, de caráter 
científico. No entanto, para que ocorra esta cisão, diferentes dimensões deverão ser consideradas, sejam elas técnicas, econômicas, políticas, de cunho profissional, institucionais e socioculturais. Assim, haverá um jogo de tensões que implicará numa renegociação de como se valorar e reconhecer os saberes da experiência, de fato, dos sujeitos implicados.

Têm-se, de um lado, a educação de cunho formal, com uma dimensão de currículo atribuída do valor da cientificidade e do reconhecimento, e de outro lado, o valor dos saberes experienciais constituídos pelos sujeitos, e que num primeiro momento, necessitam de processos de formalização e explicitação, pois, em sua própria concepção, são saberes de natureza tácitos e implícitos. Assim, as práticas educativas terão a tarefa de identificá-los, nomeá-los, dar-Ihes visibilidade e caráter de legitimidade.

Ao se pôr em destaque o valor dos saberes experienciais obtidos a partir historicidade de vida do sujeito, coloca-se em entrecruzamento as experiências na vida pessoal, profissional e social. A observação desta historicidade toma a forma de reconhecimento, bem como explicita Pires (2007, p.8): “A experiência é considerada como uma fonte legítima de saber, que pode (e deve) ser formalizado e validado".

Assim, parte-se da definição de que espaços de aprendizagem (PIRES, 2007) podem ser identificados como:

- $\quad$ Formais, os quais são espaços do sistema de educação/formação regulamentados e institucionalizados. Com isso, as aprendizagens ocorrem de forma estruturada, orientada e intencional, conduzindo à obtenção de qualificações e diplomas;

- Não-formais, que ocorrem em contextos como o de trabalho, a da comunidade, o da vida associativa, e outros. Ou seja, num ambiente estruturado e que possui intencionalidade. No entanto, as aprendizagens não conduzem necessariamente à certificação;

- Informais, que ocorrem como resultado de situações amplas de vida, em todos os aspectos, como no social ou no familiar. Assim, existindo em ambientes não estruturados para tal e onde não há intencionalidade, e com frequência, a aprendizagem não possui o reconhecimento (em âmbito individual e social).

Com isso, a reflexão direciona aos espaços de aprendizagens não-formais e informais, pois os mesmos indicam a implementação de uma perspectiva a respeito dos saberes experienciais, os quais devem ser entendidos, balizados por um quadro teórico de referência, e, 
corroborando com Pires (2007, p.10), destaca-se o conceito de aprendizagem experiencial, "a aprendizagem experiencial diz respeito a um processo dinâmico de aquisição de saberes e de competências (múltiplos e diversificados, tanto quanto à sua natureza como ao tipo de conteúdo), que não obedece uma lógica cumulativa e aditiva, mas sim, de recomposição [...]".

Assim, num viés que observa a integralidade do processo de desenvolvimento do sujeito, afirma-se que os saberes experienciais não são uma simples aplicação de saberes teóricos, pois os mesmos advêm de uma diversidade de contextos e de situações. Com isso, práticas que suportem reconhecimento e validação devem seguir o caminho de uma observação de caráter integral e coerente com a perspectiva da aprendizagem experiencial dos sujeitos em suas trajetórias de vida.

É necessário atentar-se a uma observação importante no momento de reconhecimento e validação, pois não são experiências que serão reconhecidas e validadas, porém, as aprendizagens e competências, advindas dos saberes experienciais, elaborados durante o processo de aprendizagem experiencial. Nessa perspectiva, para que uma experiência tenha o caráter de ser gestora de saberes, a mesma deve passar pelo processo de reflexão e internalização por parte do sujeito, e agir para uma transformação identitária, vista aqui como um processo inacabado e em constante elaboração e construção, pois o sujeito, ao rememorar e refletir sobre as suas práticas da experiência e, consequentemente, sobre as aprendizagens e os saberes aí implicados, reelabora com vistas à identificação dos conhecimentos e das competências daí resultantes.

Pode-se assim dizer, conforme Pires (2007, p.11), que "[...] este trabalho de explicitação (do implícito para o explícito, do invisível para o visível), mediado pela linguagem, frequentemente só é conseguido com o apoio e suporte de técnicos especializados [...]".

Constata-se, deste modo, o papel e a importância da figura docente neste processo, pois o balanço que o sujeito faz de suas aprendizagens integra dimensões tanto de retrospecção como também, de prospecção ${ }^{10}$, pressupondo que para o processo de reconhecimento e validação, necessite do aval de um sujeito habilitado e legitimado para tal. Com isso, o papel do/da docente

\footnotetext{
10 Retrospecção é vista aqui no sentido de lançar o olhar para o passado, numa observação de tempos, coisas ou acontecimentos passados. Já prospecção, refere-se ao sentido de examinar, estudar, sondar saídas, que a situação atual ao qual o sujeito se encontra, possa oferecer.
}

Periódico Horizontes - USF - Itatiba, SP - Brasil - e020061 
também se esbate na ajuda ao sujeito, que detentor de conhecimentos experienciais, adquiridos ao longo da vida, tenha estes conhecimentos organizados de tal maneira, que os mesmos servirão de ponto de partida para as aprendizagens futuras. Nessa perspectiva, a dodiscência também promoverá alterações/aprendizagens à prática docente desenvolvida.

Não se pode deixar de lado que, na atualidade, boa parte dos modelos de educação e formação para o trabalho se baseiam em competências, e que estes referenciais servem de norteadores para o reconhecimento e validação de saberes. Com o apoio de Le Boterf apud Pires (2007, p.12), "[...] a competência é uma construção social e depende das convenções ou dos pontos de vista que se adoptam; as competências existem em função do julgamento feito sobre elas, tendo como referência um dispositivo [...]".

Portanto, o reconhecimento de saberes experienciais encerra uma dimensão pessoal, individual, reflexiva, identitária e pode ser considerada como a primeira instância para o processo de validação, o qual admite a dimensão social e institucional, ou seja, aquela que detém o estatuto do formal, do oficial.

Nessa perspectiva, os saberes presentes no construto experiencial do sujeito conduzem, com o já mencionado apoio, aval e aprendizagens adquiridas nessa relação, pelo docente, à obtenção de diplomas/certificados/qualificações, levando consequentemente à elevação da autoestima e da autoimagem dos estudantes da EJAI, ao reconhecimento das histórias de vida desses estudantes e os conduzindo, por vezes, a uma ascensão profissional e econômica, individual e familiar.

\section{A análise de discurso: um dispositivo teórico-analítico auxiliando a revelar e desnudar implícitos}

A Análise de Discurso $(A D)$ nos auxiliará a perceber o modo de funcionamento discursivo na condição de haver ou não o reconhecimento e validação de saberes, a partir das falas de dois estudantes egressos da Educação Profissional. Para tanto, faz-se necessário apontar alguns de seus pressupostos.

O nascimento da Análise de Discurso francesa está atrelado a uma proposta de intervenção política que "[...] aparece como portadora de uma crítica ideológica apoiada em uma arma científica" (GADET, 1993, p.8), cujo objetivo é o de combater o formalismo linguístico, a 
automatização presente na relação com a linguagem. A AD no Brasil ou Escola Brasileira de Análise de Discurso amadureceu e se consolidou no campo dos estudos da linguagem realizados pelas Ciências Humanas, recebendo influências tanto dos estudos clássicos da análise do discurso europeia como da americana. Os estudos realizados na França por Michel Pêcheux ganharam desdobramentos e diferenciações que contribuíram para a manutenção e desenvolvimento dessa linha de pesquisa no Brasil, especialmente conduzida pela pesquisadora Eni Orlandi, na década de 70.

Araújo (2010) nos indica que a AD tem como finalidade compreender como a linguagem funciona e, nessa perspectiva, desloca da Linguística os conceitos de língua e de texto e traz das Ciências Sociais para o âmbito dos estudos da linguagem, em uma releitura, as noções de sujeito, de história e de ideologia, como elementos estruturantes do funcionamento da linguagem. Nesse contexto, a $A D$ se distancia da dicotomia saussureana entre língua e fala e vai para a instância onde os sentidos são produzidos: o discurso.

Parafraseando Orlandi (2009), a AD tem por finalidade entender como um objeto simbólico produz sentidos, como ele está investido de significância para e por sujeitos. Nesse processo de significação, a autora faz a distinção entre interpretação e compreensão dos sentidos. A interpretação estaria próxima do texto empírico, é o sentido pensando-se a partir do contexto (a relação superficial das frases entre si, o entorno verbal) e do contexto imediato. Compreender é saber como um objeto simbólico (enunciado, texto, pintura, música etc.) produz sentidos.

A $A D$ tem no discurso o seu objeto de investigação científica. No entanto, para a $A D$, o discurso é a linguagem em funcionamento - materializado em um texto - no qual o sujeito discursivo atribui sentidos, significando o mundo e, simultaneamente, significando-se. 0 entendimento do discurso tem na $A D$ um arcabouço teórico-analítico que possibilita a desnudação de como os sujeitos e sentidos são produzidos. O dispositivo analítico é construído pelo próprio analista e o primeiro passo a ser dado é a formulação da questão que desencadeará a análise. Em nosso caso, quais presenças nos discursos a respeito da interface entre saberes experienciais e epistêmicos, observados por dois sujeitos advindos do ensino técnico profissionalizante de nível médio de uma escola pública da rede estadual do Rio Grande do Sul? Conforme Araújo (2010), a ideologia é conceito estruturante na AD, que assume novos 
contornos, porque se desloca de um conceito sociológico para um conceito linguístico-discursivo: a ideologia interpela o indivíduo em sujeito, levando-o a ocupar um lugar em uma determinada formação social, de onde ele se posiciona discursivamente, acreditando ser o dono do seu dizer e da sua vontade. O sujeito, dessa maneira, se submete à ideologia pelo efeito da literalidade, pela evidência dos sentidos.

Então, a ideologia, na $A D$, não é compreendida como conjunto de representações, ou visão de mundo ou como ocultação da realidade, mas sim, como resultado da relação do sujeito com a língua e a história, conduzindo para que haja o sentido. Portanto, o sujeito discursivo é ideologicamente "assujeitado" a uma formação discursiva, entendida como que, numa formação ideológica dada, regula o que pode e deve ser dito.

Para a $A D$, o interdiscurso é o lugar no qual se constroem sentidos sociais que formam a memória dos já-ditos que vigoram na sociedade, configurado em forma de rede, onde os sentidos estão entrelaçados. Dessa forma, o interdiscurso é parte constitutiva dos sentidos, sustentando as possibilidades do dizer, uma vez que vincula esse dizer a uma memória, identificando-o em sua historicidade e evidenciando seus compromissos políticos e ideológicos. Demonstrando que o interdiscurso é do nível da constituição do sentido, o intradiscurso é do nível da formulação; aquele que realiza o trabalho de juntar os sentidos dispersos no texto. Assim, o intradiscurso é a representação material do interdiscurso (dos já-ditos) constituído pelas sequências discursivas enunciadas pelo sujeito.

Pode-se falar que na memória há a presença de um estatuto de implícitos, o qual tem o seu funcionamento baseado em conteúdo memorizado, historicamente. Do ponto de vista discursivo, o implícito trabalha, portanto, sobre a base de um imaginário que representa como memorizado. Com isso, cada discurso faz apelo à (re)construção deste imaginário, calcado em respeito às formas que permitem sua inserção na paráfrase (sem poder provar que este implícito (re)construído tenha existido como discurso autônomo (ORLANDI, 2009). Os processos parafrásticos são aqueles pelos quais em todo dizer há sempre algo que se mantém, isto é, o dizível, a memória. A paráfrase representa assim o retorno aos mesmos espaços do dizer. Produzem-se diferentes formulações do mesmo dizer sedimentado.

Os elementos enunciativos que estes implícitos comportam propõem que o funcionamento do discurso em relação aos seus ditos operadores linguageiros funcionem com 
relação à imersão em uma situação. Em outras palavras, sendo o passado memorizado, o discurso só pode trabalhar mediando reformulações que o direcione no discurso concreto ao qual se encontra. O que coloca em cena uma negociação entre o choque do acontecimento histórico singular e o dispositivo complexo de uma memória que coloca em jogo uma crucial passagem do visível ao nomeado, no qual a imagem seria um operador de memória social, comportando no interior dela mesma um programa de leitura, um percurso escrito discursivamente em outro lugar - restabelecido pelos implícitos através do efeito da repetição e da regularização: a condição do legível em relação ao próprio legível.

Para atribuir sentidos à unidade, as ocorrências de repetição devem ser tomadas por uma regularidade (esta não deduzida no corpus). Cita-se como exemplo: ocorrência em diversos textos, diferentes posições, que permitem estabelecer suas regularidades e os implícitos clamados. Na AD há uma dialética entre repetição e regularização, que em termos linguísticos significa que o corpus nunca apenas é suficiente para fundar a gramática, indicando que a regularização repousa sobre um jogo de forças, tendo o sentido como "limite". Com isso, o fechamento exercido por todo um jogo de força de regularização se exerce no sentido de retomada de discursos, ou seja, a regularização se apoia sobre o reconhecimento do que é "repetido", da ordem do formal, sem necessariamente ser gráfico ou fônico (atentemo-nos ao jogo simbólico que permite este reconhecimento). Porém, há também um jogo de desregulação que atua gerando a polifonia ${ }^{11}$, como um jogo de tensão e de conflitos entre sentidos e que produzem os deslocamentos, entre os sentidos e o dizer, e entre as formações discursivas.

Faz-se necessário reconhecer que as condições como os sujeitos produzem os discursos são, também, de fundamental importância para a compreensão dos sentidos formulados. As condições de produção estabelecem relação entre a linguagem e a exterioridade e comportam os mecanismos de funcionamento do discurso - relações de sentido, relações de forças e mecanismo de antecipação - e as formações imaginárias - elementos estruturantes do

\footnotetext{
${ }^{11}$ Polifônico, gênero denominado por Mikhail Bakhtin (1895-1975) que apresenta vários pontos de vista e várias vozes, cada qual recebendo do narrador o que lhe é devido. Bakhtin defendeu a ideia de que todo texto é um objeto heterogêneo, de que todo texto é constituído por várias vozes, é a reconfiguração de outros textos que lhe dão origem, dialogando com ele, retomando-o. Os sujeitos se constituem como tais nas ações interativas, sua consciência se forma no processo de interiorização de discursos preexistentes, materializados nos diferentes gêneros discursivos, atualizados nas contínuas e permanentes interlocuções de que vão participando (BRAIT, 2000).
} 
discurso que determinam o lugar em que os interlocutores atribuem a si mesmo e ao outro na situação discursiva, por meio de projeções de imagens. Para Pêcheux (1993), as formações imaginárias são elementos estruturantes do processo discursivo, uma vez que elas determinam o lugar que os protagonistas da situação de interlocução atribuem a si mesmo e ao outro, durante a formulação do dizer.

\section{Contornos do caminho: os sujeitos e seus discursos}

Com o apoio do arcabouço teórico-metodológico da Análise de Discurso de Linha Francesa, propõe-se a reflexão sobre os discursos a respeito da interface entre os saberes experienciais e epistêmicos, observados por dois sujeitos advindos do ensino técnico profissionalizante de nível médio de uma escola pública da rede estadual do Rio Grande do Sul. Em sentido de demarcar o objeto de estudo a partir das subjetividades que circulam nos discursos dos sujeitos, optou-se pela pesquisa de tipo qualitativa, por afirmar a relevância dos atores sociais, a significação dos valores ético-políticos, a interdependência entre a teoria e a prática e pelo fato de os pesquisadores comprometem-se com a prática, a emancipação humana e a transformação social (FLICK, 2013).

Nessa perspectiva, a entrevista constitui-se num instrumento relevante para a coleta de dados. Assim, sob orientação, da pesquisa qualitativa, em formato semiestruturado, efetivou-se um questionário, realizado individualmente, em dezembro de 2018, contendo seis perguntas, com o objetivo de buscar informações sobre os respondentes. Os mesmos foram enviados aos participantes através da ferramenta de comunicação de celulares WhatsApp ${ }^{12}$.

Os participantes da pesquisa atuam num departamento de uma empresa pública de concessão de energia e, conforme afirmam, os saberes advindos das suas trajetórias de vida e das suas experiências escolares formativas se entrecruzam no cotidiano do convívio profissional. Ambos estudaram na mesma escola, localizada na região metropolitana, centenária e bastante conhecida localmente pela formação técnico-profissional que oferta. São sujeitos de idades distintas, porém, com percursos de vida profissionais relativamente parecidos. Ambos, entraram

\footnotetext{
${ }^{12}$ É um aplicativo multiplataforma de mensagens instantâneas e chamadas de voz para smartphones. Cujo desenvolvedor é WhatsApp Inc. Facebook Inc.
}

Periódico Horizontes - USF - Itatiba, SP - Brasil - e020061 
para o mercado de trabalho, exercendo atividades profissionais ligadas à área técnica sem formação específica alguma, realizando a aquisição de seus saberes com o desenrolar da prática.

O primeiro, denominado Artur, nome fictício, de 37 anos de idade. Trabalha na área elétrica há 21 anos, sendo funcionário da empresa de concessão de energia há 17 anos. Formouse em Técnico em Eletrotécnica no ano de 2015. É casado e não possui filhos. O segundo, Pedro, nome fictício, de 53 anos de idade, trabalha na área técnica de eletricidade há 33 anos, sendo funcionário da empresa de concessão de energia aos mesmos 33 anos. Formou-se em Técnico em Eletrotécnica, na modalidade subsequente ${ }^{13}$ no ano de 1990. É casado e pai de dois filhos já adultos.

$\mathrm{Na}$ tessitura dos discursos dos sujeitos é percebida a relação aos sentidos que eles atribuem ao reconhecimento e validação que a escola técnica profissionalizante lhes forneceu, aos seus saberes experienciais, advindos de suas experiências de vida, quando do momento em que frequentavam a escola. No sentido de saber como percebem esse processo, efetivou-se questionamento se, na época em que estudavam na escola técnica, os seus saberes técnicos do trabalho diário e das experiências de vida que já possuíam, foram considerados importantes pelos professores. A esse respeito, assim se manifestaram:

Não foram considerados. Os professores passavam conteúdos sem distinção, de forma igual, independente do conhecimento ou experiência pessoal (ARTUR).

Foram considerados de forma individual, no sentido que isso facilitaria minha assimilação dos conteúdos propostos (PEDRO).

De um modo geral, em relação ao conteúdo das falas, ambos responderam ao solicitado; Artur, informando que seus saberes e experiências foram desconsiderados e Pedro, ao contrário, respondendo que, de forma individual, os mesmos foram considerados.

Na primeira frase enunciada por Artur "Não foram considerados", nesta oração sem sujeito, há a manifestação de um nível de negação, onde o não age sobre o próprio evento (predicado) considerados. Trata-se de uma negativa enfática, cuja ordem, a primeira em sua

\footnotetext{
${ }^{13}$ A Educação Profissional aqui será entendida como campo de conhecimento próprio e, por isso, é grafada em letra maiúscula. Por sua ocorrência na Educação Básica e, como tal, conforme a LDBEN 9394 (BRASIL, 1996), de acordo com o Artigo 36C, a EP poderá ocorrer de forma integrada, concomitante e/ou subsequente.
} 
colocação, segue de resposta a uma interrogativa geral, que compreende a indagação efetivada. Conforme Neves (2011, p.286, grifos da autora), “[...] esse NÃO que constitui um enunciado vem seguido por um novo enunciado no qual o elemento $N \tilde{O} O$ - ou outro qualquer elemento de negação entra como operador de negação".

Em "Os professores passavam o conteúdo sem distinção", a preposição "sem" reforça o sentido do "não" estabelecendo esta relação e outras relações semânticas com outros termos do enunciado, indicando privação ou ausência, ou seja, mais uma vez a negação é reforçada. Assim, os conteúdos, "sem distinção" eram passados, "independente do conhecimento ou experiência pessoal", afirma e reitera Artur.

Este nível de negação indica um certo caráter de subalternidade, de imposição, de desconsideração, pois ao não serem considerados os seus saberes técnicos do trabalho diário e das experiências de vida, desvaloriza-se toda e qualquer importância que o conhecimento prévio da experiência de vida e profissional poderia agregar ao conhecimento epistêmico escolar.

Quando enuncia "independente do conhecimento ou experiência pessoal", Artur indica, também, que os conteúdos escolares eram transmitidos "sem distinção" por parte dos docentes, de como ele mesmo denomina "forma igual". Tem-se que esta expressão marca que o tipo de conhecimento transmitido já estava formatado, encapsulado, não permitindo qualquer liberdade criativa por parte do aluno. Do ponto de vista ideológico, pode-se pensar que esta escola, na engrenagem social capitalista, funcione como conversora de realidades sociais em realidades escolares, reproduzindo as relações de exclusão e reafirmando sua posição como aparelho ideológico, que, de acordo com Althusser (1970), apresenta discursos proferidos e práticas aceitas em seus espaços legitimando a prerrogativa estipulada pelo Estado. Conforme indicado nesta fala, o Discurso Pedagógico proferido, presente e reproduzido na memória discursiva de Artur, tendia para o discurso autoritário, o qual, conforme Orlandi (1983), não permite a reversibilidade, é dotado de cortes polissêmicos e conduz a compreensões unívocas. Nesta perspectiva, pode-se falar num tipo de educação preparatória para o mercado de trabalho e que coíbe toda e qualquer variante que possa surgir. A esse respeito, torna-se importante considerar que a Educação Profissional acumula uma memória interdiscursiva histórica, com tendência a uma concepção de docência com viés instrumental (FERRETI, 2010). Essa forma de conceber a docência a reduz ao ensino, de forma tecnocrata, conteudista, da Educação Bancária, 
criticada por Freire (1986; 2000). Essa concepção e essa escola, aparentemente e implicitamente não nomeada, se presentifica nos dizeres de Artur.

Já no discurso de Pedro, como resposta à pergunta feita, o mesmo indica que seus saberes experienciais foram considerados, mas, em caráter de restrição, como ele mesmo expressa, eram "considerados de forma individual". Portanto, os mesmos serviriam na condição em que facilitariam a assimilação dos conteúdos propostos, ou seja, trariam certa familiaridade, mas não corroborariam como conteúdo epistêmico a ser aproveitado, evidenciando o caráter de supremacia dos conhecimentos da escolaridade formal. Seguindo em sua resposta, há nova manifestação da negação, pois os seus saberes experienciais não contribuiriam para o grupo (negação direta), o qual Pedro chama de coletivo (grupo dos pares). Novamente, vê-se um apagamento de todo o saber experiencial pregresso, e este, se manifesta sendo sobreposto por um saber "já lá aí" (PÊCHEUX, 1993) pré-definido, formatado e não aberto a interdições e processos criativos.

Uma observação comum aos discursos de Artur e Pedro, em suas respostas, é o caráter de manifestação da negação de seus conhecimentos por parte dos professores, o que, de certa forma, exibe claramente a força ideológica da escola como aparelho de reprodução, de dominação e apagamento de memórias, indicando para um caminho de subserviência, onde se deve obedecer e acatar conhecimentos válidos e certificáveis (não abrindo possibilidades a caminhos alternativos). Mais uma vez, retorna, nesse dizer, um efeito parafrástico: o da memória histórica e institucionalizada da escola (ORLANDI, 1983) constituída por uma docência, também reduzida a ensino e que se constitui, por movimentos e modelos pedagógicos que visam à "assimilação dos conteúdos propostos".

No processo de ensino e aprendizagem desenvolvido nas salas de aula desses sujeitos, observou-se, no campo dos saberes epistêmicos, saberes em desacordo com as suas realidades vividas; estes baseados em conhecimentos que se constroem por conceitos em relação a um objeto idealizado, ocasionando apagamento da subjetividade, historicidade e vivência experiencial. Visando saber um pouco mais se os processos pedagógicos desenvolvidos na referida escola consideravam as realidades de trabalho dos respondentes, os mesmos manifestaram: 
Dentro do conhecimento teórico e prático básico de elétrica era próximo, mas no que se refere ao específico, no meu caso não, pois na matéria de redes foi só passado o conteúdo de redes aéreas (ARTUR, grifos nossos).

Sim, e isso me ajudou a esclarecer muitas dúvidas que já tinha anteriormente. Quando me formei já trabalhava na área há uns 15 anos (PEDRO, grifos nossos).

Mais uma vez, ambos responderam ao que Ihes fora perguntado. Percebe-se que o conteúdo presente nos dizeres de Artur informa que conhecimentos ligados à área, em caráter "teórico e prático básico", eram próximos a sua realidade de trabalho, denotando haver certa familiaridade entre os conhecimentos. No entanto, no enunciado, a presença da conjunção, "mas" denota uma relação de adversidade, que passa a figurar como oposição, denegação (NEVES, 2011), já de que em relação aos saberes específicos contidos nos conteúdos escolares passados, a sua realidade laboral estava distanciada. Ratificando este distanciamento, justifica sua posição de modo explicativo, informando: "pois na matéria de redes foi só passado o conteúdo de redes aéreas". Esse dizer de Artur, em forma de denúncia e de modo impessoal em terceira pessoa, revela um implícito: o de que há conhecimentos que se constroem por conceitos em relação a um objeto idealizado. Este modo de valorizar um conhecimento em detrimento de outro desvela um tipo de política que se manifesta pedagogicamente, que é estabelecida numa relação de currículo, na escola. A real necessidade de aprendizagem deste, enquanto aluno, que se supõe ser a de conhecer aspectos de outras modalidades de redes de distribuição de energia elétrica, Ihe foi subtraída, negada. O modo do funcionamento discursivo de Artur, que inicia com uma resposta positiva frente à consideração dos saberes referentes ao seu mundo do trabalho, em seguida, é posto em xeque. Desta forma, mais uma vez, Artur, de modo implícito fala sobre um tipo de escola, que comporta um tipo de discurso; aquele que desconsidera os seus desejos e necessidades, de forma autoritária.

Em perspectiva diferente, Pedro parece assumir uma outra posição ao responder sobre o aproveitamento dos saberes do trabalho, na escola. Ao utilizar a expressão "me ajudou a esclarecer muitas dúvidas", assume que seus saberes experienciais prévios o auxiliaram na apropriação dos novos conhecimentos. Pode-se dizer, então, que Pedro percebeu a aproximação e reconhecimento de seus saberes, num processo reflexivo individual, no entanto, o mesmo não indica que os mesmos tenham sido validados pelos professores. Assim, seus saberes 
experienciais adquiridos na história de vida "Quando me formei já trabalhava na área há uns 15 anos", que não têm sua conceptualização ${ }^{14}$ de modo efetivo pela formação escolar, produzem efeitos nesta, mesmo quando não estejam explicitados. Vê-se que um jogo de forças de regularização se exerce no sentido de retomada de discursos, porém, também há um jogo de desregulação que atua, gerando a polifonia, como um jogo de tensão e de conflitos entre sentidos, produzindo uma série de deslocamentos, entre os sentidos e os dizeres. Deste modo, embora Pedro afirme o "sim", não há informação suficiente em seu dizer para afirmar-se que, realmente, os seus saberes foram considerados por um processo político-pedagógico da escola que tenha acenado nessa direção. Pode-se dizer que, na memória discursiva de Pedro habitam julgamentos de verossimilhança, o que para ele passa a ser reconstituído pelas operações de paráfrase, reafirmando lhe, que o fato de trabalhar há quinze anos na área lhe tenha ajudado, evidenciando, assim, a posição enunciativa de um sujeito histórico.

Diante das análises efetivadas, obtém-se o seguinte quadro síntese referente a como aparecem nos dizeres, à docência, o Discurso Pedagógico e o reconhecimento dos saberes na Educação Profissional:

Quadro 1: Percepções sobre Docência, DP e Reconhecimento dos saberes

\begin{tabular}{|c|c|}
\hline Aspectos destacados & Discursos gerais predominantes \\
\hline Docência na Educação Profissional & Com viés instrumental \\
\hline Discurso Pedagógico & Autoritário \\
\hline Reconhecimento dos saberes & Desconsiderados, silenciados \\
\hline
\end{tabular}

Fonte: os autores.

Pode observar, ainda, como um implícito presente em ambos os dizeres, é que o desejo de reconhecimento e, principalmente, o de validação por parte do discurso proferido é o de que os saberes experienciais advindos do cotidiano do trabalho sirvam, de alguma forma, como embasamento para a apropriação dos conhecimentos epistêmicos do cotidiano da

\footnotetext{
${ }^{14}$ Em sentido de ação de organizar conceitos.
} 
aprendizagem formal. Outro aspecto de força mobilizadora, não dita, mas percebida, principalmente no discurso do Artur, está na questão do distanciamento e da não consideração dos saberes adquiridos em sua experiência de vida, que o leva a uma postura de tensão diante do fato. O movimento analítico nos propiciou a perceber estas faltas, que não são falhas, mas sim, apagamentos intencionais aos saberes dos estudantes.

\section{Considerações finais}

Refletiu-se, ao longo deste artigo, que promover processos de reconhecimento/validação de saberes experienciais é uma perspectiva que deve ser reconhecida e aplicada no domínio da educação de sujeitos jovens, adultos e idosos, ao passo que promovem visibilidade e legitimidade em saberes que se encontram ocultados em suas histórias de vida.

Embora se saiba que a abordagem desse processo investigativo envolveu uma amostra pequena de uma única escola, passa-se a perceber os discursos presentes como discursos em circulação, o que legitima o corpus da pesquisa pela compreensão dos dizeres sobre a Educação Profissional e pelos discursos que comporta. Assim, pode-se afirmar a representatividade de uma memória discursiva histórica que demarca o DP Autoritário, em uma acepção de docência reduzida ao ensino, com viés instrumental e, consequentemente, perspectivas de reconhecimento de saberes experienciais desconsiderados, silenciados, conforme apontam os dizeres de Artur e Pedro.

Pode-se perceber, assim, mediante análises de suas falas, que a escola ressurge como reprodutora de discursos proferidos e práticas aceitas em seus espaços, legitimando as prerrogativas estipuladas pelo Estado, de que haja competências e habilidades a serem adquiridas, mediante um tipo de educação preparatória para o mercado de trabalho, o que coíbe toda e qualquer variante que possa surgir. A esse respeito, torna-se importante considerar que a Educação Profissional acumula uma memória interdiscursiva histórica, com tendência a uma concepção de docência com viés instrumental (FERRETI, 2010).

Em contraposição, uma mudança de pensamento educativo sugere refletir sobre os saberes e quais competências são importantes na sociedade contemporânea. Num repensar de processos formais, não-formais e informais no campo da Educação Profissional e, sobretudo, na 
formação docente a ser constituída a partir da proposição, que deverá se atentar não só para as especificidades desta modalidade de educação, mas incluir em seus quadros de reconhecimento, a existência de saberes que se constituam ao longo das histórias de vida dos sujeitos.

O que se pode observar, ainda, como implícitos presentes nos dizeres, é que o desejo de reconhecimento e, principalmente o de validação por parte do discurso proferido é o de que os saberes experienciais advindos do cotidiano do trabalho sirvam, de alguma forma, como embasamento para a apropriação dos conhecimentos epistêmicos do cotidiano da aprendizagem formal. Outro aspecto de força mobilizadora, não dita, mas percebida, está na questão do distanciamento e da desconsideração dos saberes adquiridos em sua experiência de vida.

Diante desse contexto, a Educação Profissionalizante não pode deixar de lado suas características singulares e normativas em sua trajetória, que, conforme Fischer e Franzoi (2009), tem a categoria trabalho assumida pela EP e necessita promover uma formação humana incorporada em projetos de formação integral de jovens, adultos e idosos trabalhadores "[...] como tarefa histórica, política, coletiva que depende de experimentação. [...] Como pano de fundo, está a discussão do sentido político da formação (geral e profissional) de trabalhadores e da teoria pedagógica que a sustenta" (p.48).

Propõe-se, assim, como um elemento central à Educação Profissional, a necessidade de se distanciar da equação: Educação Profissional para o capital, para o emprego etc. O que se deve ter como foco reflexivo é como os vínculos, aqui vistos na forma de saberes da vida, do trabalho e da educação, se interliguem e passem a conduzir processos de formação humana que visem à estruturação de sujeitos em sentido amplo e integral para a vida e para sociedade.

Portanto, para tratar da importância e da força que o reconhecimento e validação dos saberes experienciais possuem na formação dos sujeitos, necessita-se considerar que ambos devem estar contemplados de modo claro nas políticas e práticas voltadas à educação, pois, memórias discursivas convocadas no movimento de interpretação proposto, trazem consigo uma memória de saberes desvalorizados e, consequentemente, apagados na formação escolar. 


\section{Referências}

ALCOFORADO, L. M. Reconhecimento, validação e certificação de saberes experienciais: desafios para a formação continuada e as relações de trabalho. Trabalho \& Educação, Belo Horizonte, v.23, n.3, p.13-30, set-dez. 2014.

ALTHUSSER, L. Ideologia e aparelhos ideológicos do estado: notas para uma investigação. Trad. Joaquim J. M. Ramos. Lisboa: Editorial Presença/Martins Fontes, 1970.

ARAÚJO, I. S. Usos funcionais da escrita na história de vida dos atores da educação de jovens e adultos da Escola Municipal de Bananeiras / Ilha da Maré - Salvador - BA. 2010. $152 \mathrm{f}$.

Dissertação (Mestrado em Educação e Contemporaneidade) - Universidade do Estado da Bahia, Salvador, 2010.

BRAIT, B. Anotações em sala de aula. São Paulo: PUC, 2000.

BRASIL. Lei no 5.692, de 11 de agosto de 1971. Fixa as diretrizes e bases para o ensino de 10 e 2ำ graus, e dá outras providências. Disponível em:

http://www.planalto.gov.br/ccivil_03/Leis/L5692.htm. Acesso em: 30 dez. 2019.

BRASIL. Constituição da República Federativa do Brasil de 1988. Disponível em:

https://www.planalto.gov.br/ccivil_03/constituicao/constituicao.htm. Acesso em: 20 dez. 2019.

BRASIL. Lei no 9.394/1996, de 20 de dezembro de 1996. Estabelece as diretrizes e bases da educação nacional. 2016. Disponível em:

http://www.planalto.gov.br/ccivil_03/LEIS/L9394.htm. Acesso em: 30 dez. 2019.

BRASIL. Lei no 11.741, de 16 de julho de 2008. Altera dispositivos da Lei no 9.394, de 20 de dezembro de 1996, que estabelece as diretrizes e bases da educação nacional, para redimensionar, institucionalizar e integrar as ações da educação profissional técnica de nível médio, da educação de jovens e adultos e da educação profissional e tecnológica. Disponível em: http://www.planalto.gov.br/ccivil_03/_Ato2007-2010/2008/Lei/L11741.htm. Acesso em 30 dez. 2019.

BRASIL. Lei no 13.415 de 13 de fevereiro de 2017. Regulamenta o Fundo de Manutenção e Desenvolvimento da Educação Básica e de Valorização dos Profissionais da Educação, a Consolidação das Leis do Trabalho - CLT, aprovada pelo Decreto-Lei no 5.452, de 01 de maio de 1943, e o Decreto-Lei № 236, de 28 de fevereiro de 1967; revoga a Lei no 11.161, de 05 de agosto de 2005; e institui a Política de Fomento à Implementação de escolas de Ensino Médio em Tempo Integral. Disponível em: http://www.planalto.gov.br/ccivil_03/_Ato20152018/2017/Lei/L13415.htm. Acesso em: 30 dez. 2019.

DUTRA, M. J. T. S.; Sant' Anna, S. M. L.; ESPINDULA, C. G. Os sentidos da EJA nas vozes de estudantes do Ensino Médio de uma escola estadual no Rio Grande do Sul. In: Aline Silva de 
Bona. (Org.). Práticas, experiências e fazeres na educação: uma diversidade em prol da complexidade. 1ed. Curitiba: CRV, p. 69-86, 2019.

FERRETI, C. J. Educação profissional. In: OLIVEIRA, D. A.; DUARTE, A. M. C.; VIEIRA, L. M. F. (orgs.). Dicionário: trabalho, profissão e condição docente. Belo Horizonte: UFMG/Faculdade de Educação, 2010. Disponível em: https://gestrado.net.br/verbetes/educacao-profissional/. Acesso em 28 dez. 2019.

FISCHER, M. C. B.; FRANZOI, N. L. Formação humana e educação profissional: diálogos possíveis. Educação Sociedade e Culturas, n.29, p.35-51, 2009.

FLICK, U. Introdução à metodologia de pesquisa: um guia para iniciantes. Trad. Magda Lopes. Porto Alegre: Penso, 2013.

FREIRE, P. Pedagogia do oprimido. São Paulo: Paz e Terra, 1986.

FREIRE, P. Pedagogia da autonomia: saberes necessários à prática educativa. São Paulo: Paz e Terra, 1997.

FREIRE, P. Pedagogia da esperança: um reencontro com a pedagogia do oprimido. São Paulo: Unesp, 2000.

GADET, F. Por uma análise automática do discurso: uma introdução à obra de Michel Pêcheux. Campinas: Editora da Unicamp, 1993.

JUNIOR, W. P. M.; MAUÉS, O. C. O. Banco Mundial e as políticas educacionais brasileiras. Educação \& Realidade, Porto Alegre, v.39, n.4, p.1137-1152, out-dez. 2014.

LAFFIN, M. H. F. A constituição da docência entre professores de escolarização inicial de jovens e adultos. Ijuí: Unijuí, 2013.

NEVES, M. H. M. Gramática de usos do português. 2 ed. São Paulo: Unesp, 2011.

OLIVEIRA, R. S. A docência na educação profissional e tecnológica: formação, saberes e experiências. Plurais Revista Multidisciplinar. v.1, n.3, p.68-78, 2016. Disponível em: https://www.revistas.uneb.br/index.php/plurais/article/view/3059/1992. Acesso em: 22 ago. 2018.

ORLANDI, E. P. A linguagem e seu funcionamento: as formas do discurso. São Paulo: Brasiliense, 1983.

ORLANDI, E. P. Discurso e leitura. 8. ed. São Paulo: Cortez, 2008.

ORLANDI, E. P. Análise de discurso: princípios e procedimentos. 8. ed. Campinas: Pontes, 2009. 
PÊCHEUX, M. Análise automática do discurso (AAD). In: GADET, F.; HAK, T. Trad. Bethania S. Mariani et al. (orgs.). Por uma análise automática do discurso: uma introdução à obra de Michel Pêcheux. Campinas: Unicamp, p.61-162, 1993.

PIRES, A. L. O. Reconhecimento e validação das aprendizagens experienciais: uma problemática educativa. Sísifo, Revista de Ciências da Educação. n.2, p.5-20, jan.-abr. 2007. Disponível em: http://sisifo.fpce.ul.pt. Acesso em: 07 jan.2020.

RIBEIRO, A. F. Modelos de produção. Taylorismo, fordismo e toyotismo. Lutas Sociais, v.19, n.35, p.65-79, dez. 2015. Disponível em: https://revistas.pucsp.br/ls/article/view/26678. Acesso em: 03 fev.2020.

ROSA, C.; SANT' ANNA, S. M. L.; STRAMARE, O. A. Sentidos de qualidade: vozes de professores e estudantes egressos da EJA no ensino superior. Revista de Educação Pública, v.28, n.67, p.1537, jan.-abr. 2019.

SANTOS, S. V. Seminário especial: diálogos freireanos na educação de jovens, adultos e idosos, 2019, Porto Alegre. Universidade Federal do Rio Grande do Sul - UFRGS, Faculdade de Educação, Programa de Pós-Graduação em Educação. Disponível em: https://www.ufrgs.br/ppgedu/wpcontent/uploads/2017/.../Simone_Valdete_SE.pdf. Acesso em: 01 jul. 2019.

Recebido em fevereiro 2020.

Aprovado em agosto 2020. 